\title{
Itálica Virtual. \\ Un proyecto educativo que hace Historia
}

\author{
Alfredo Grande León \\ Conservador y Restaurador de BB.CC. \\ Colegio de San Francisco de Paula. Sevilla
}

\section{Resumen}

Desde 1996, el Colegio de San Fransico de Paula de Sevilla, desarrolla un proyecto pedagógico sin precedentes en la educación española: Itálica Virtual. En el presente artículo describimos su historia, objetivos y la metodología propia seguida para su ejecución.

\section{Palabras clave}

llusión / Historia / Pedagogía / Tridimensional / Evocación / Educación / Trabajo en equipo / Creatividad.

\section{Introducción}

Si nos remitimos al desarrollo de la historia del arte, la captación de la realidad ha sufrido una gran evolución. El afortunado invento de la perspectiva constituye un paso importante en la visualización del espacio. Sin embargo, es un recurso muy limitado, porque no es más que una representación plana de un espacio tridimensional. El término perspectiva se utiliza a veces en un sentido amplio para abarcar sistemas proyectivos normalizados en general, pero aquí nos interesa el sentido más estricto, de lo que denominamos perspectiva óptica'. Las maquetas resuelven este problema, pero aíslan al humano como observador externo y colocan a la escala en una barrera infranqueable para integrarse en el espacio.

Ha tenido que pasar mucho tiempo para poder acceder a la representación 3D del espacio, en un ambiente generado que permite al usuario sentir, en cierta medida, que está en el lugar representado, experiencia aún más singular si se realiza en un espacio histórico.

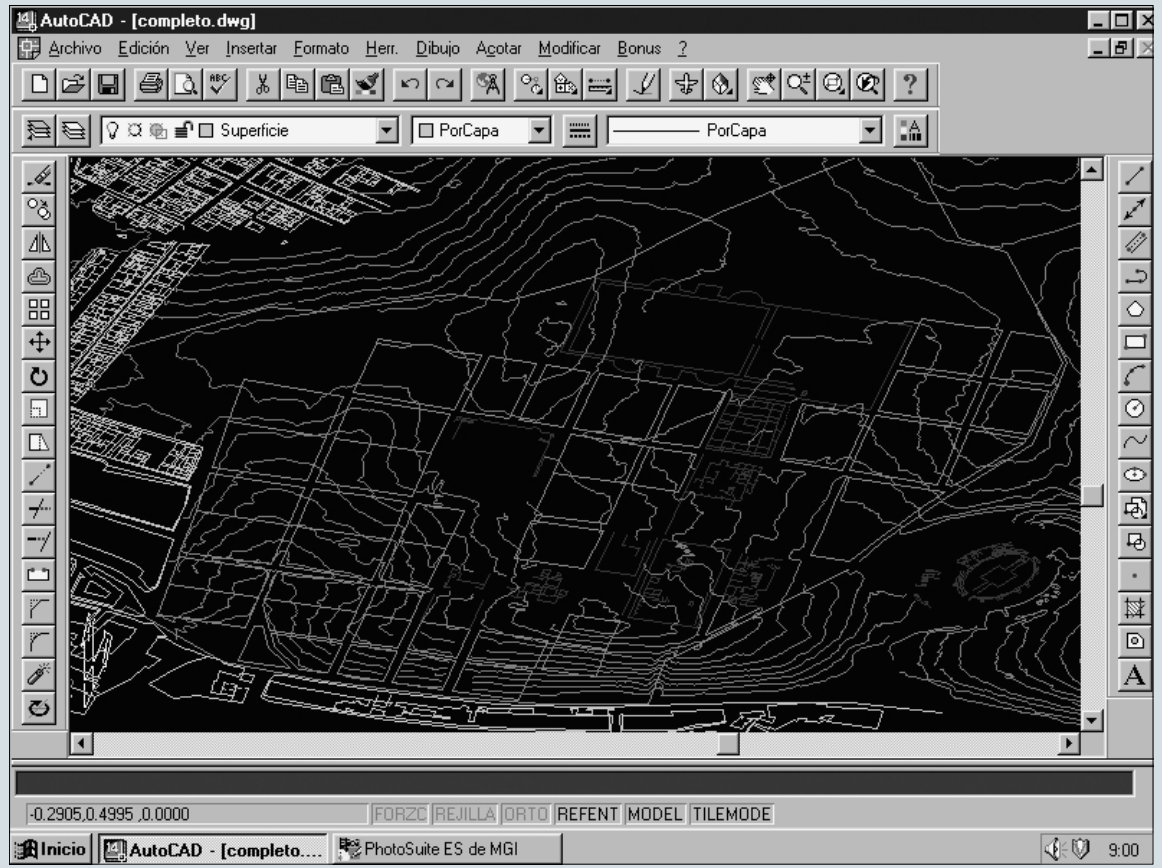

\section{Nuevas tecnologías}

Introducidos ya en un nuevo milenio, se hace necesario replantear nuestro pensamiento. $\mathrm{E}$ manejo de la gran cantidad de información que existe en el mundo sólo es posible gracias a la tecnología actual; es obvio entonces, que las herramientas informáticas pueden transformarse en un poderoso aliado de la historia. En el mundo antiguo la memoria estaba concebida como parte de la retórica, siendo la memoria espacial más frágil que la palabra y luego pasó a ser escrita... inos pueden ayudar las nuevas tecnologías a recuperar memoria?

Las posibilidades que brinda la informática deben ser tenidas seriamente en cuenta, para aprovecharnos de ese horizonte abierto por los medios digitales, en especial de las nuevas tecnologías infográficas, que con sus prestaciones están revolucionando las áreas de la creación audiovisual.

A través de la infografía y, en concreto, de las aplicaciones 3D, podemos crear escenarios virtuales en el ordenador y obtener de él imá- genes fijas y animaciones. En la actualidad esta técnica se utiliza ampliamente en numerosos campos, donde constituye una herramienta valiosísima. El uso de la representación $3 \mathrm{D}$ en el campo del Patrimonio Histórico es una de las últimas y efectivas aplicaciones; el evidente retraso en su utilización se puede deber a un abismo entre los arqueólogos y los informáti$\cos ^{2}$. Los recursos tridimensinales son atractivos a un amplio espectro de público, desde el de los arqueólogos, historiadores y profesionales cuyas hipótesis son puestas en práctica, al área docente y de formación, como método de restauración no destructivo o como vehículo lúdico para el gran público que puede deleitarse viendo lo que fue, frente a lo que es. Lo que no podemos olvidar es que el diseño asistido por ordenador es una magnífica herramienta, pero que en ningún caso debe luchar con la dimensión artística tradicional. El diseño manual, las maquetas, el fotomontaje, las técnicas de representación pictórica (témpera, acuarela, gouache, etc.), son métodos válidos de representación de la realidad de manera autónoma o formando parte de la representación tridimensional digital. 


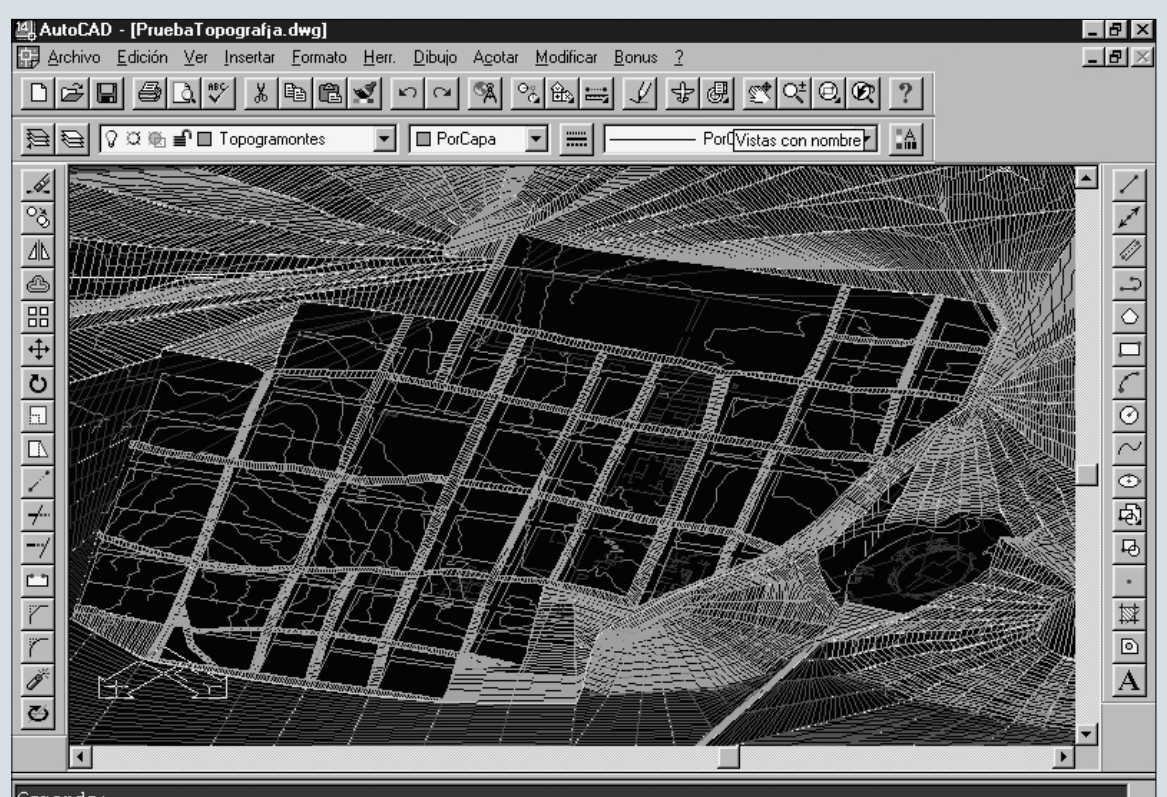

Crea y restituye vistas: ddview

Anicio 国|AutoCAD - [PruebaTo...

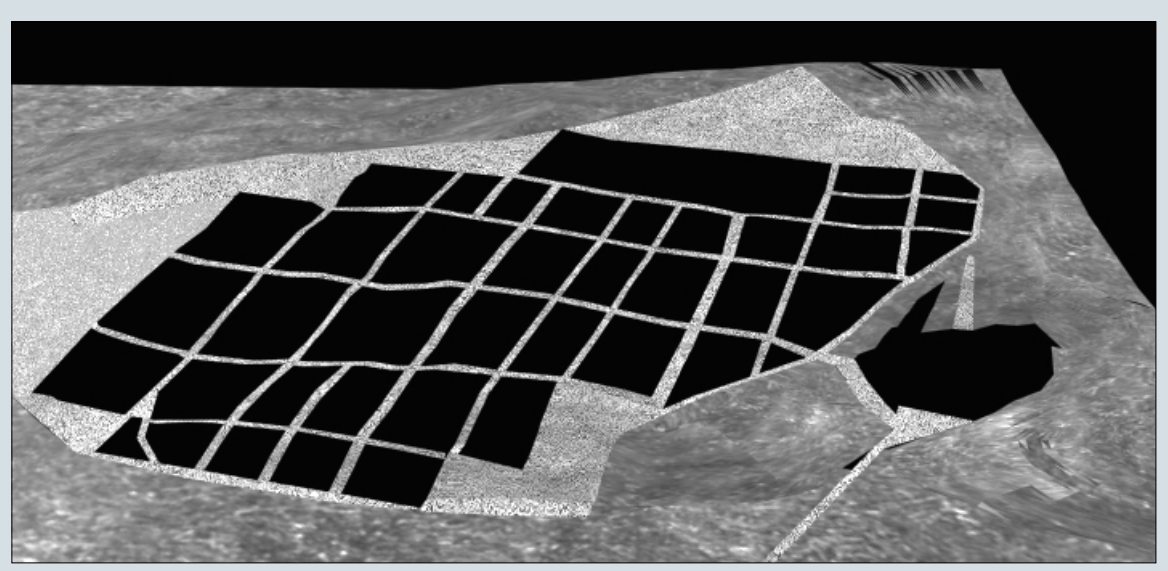

\section{Itálica Virtual}

El proyecto Itálica Virtual constituye uno de los proyectos más ambiciosos que se ha planteado el Colegio sevillano de San Francisco de Paula en sus más de cien años de antigüedad. Trata de reconstruir la ciudad romana de Itálica, Santiponce, Sevilla, por medio del diseño asistido por ordenador CAD y la realidad virtual. Su objetivo es sobrevolar la ciudad, pasear por sus calles, entrar en sus edificios, evocar su historia, una singular anastilosis ${ }^{3}$, que retoma el pasado, lo actualiza y nos ayuda a entender el presente.

Para situar el yacimiento en la historia, hemos elegido como parámetro espacial la ciudad romana completa, su recinto amurallado y sólida hipótesis, resultado de un arduo proyecto de investigación. Para ello, y liderando un equipo multidisciplinar de topógrafos, historiadores, artistas y restauradores, contamos con el asesoramiento histórico/arqueológico de D. José Manuel Rodríguez Hidalgo, exdirector del Conjunto Arqueológico de Itálica, artífice de la dimensión urbana actual de la ciudad y del Proyecto Itálica de prospecciones geofísicas de 1991, con el apoyo de D. José María Luzón, también exdirector de Itálica y experto en el yacimiento, así como del Departamento de Historia Antigua de la Facultad de Geografía e Historia de la Universidad de Sevilla y del Museo Arqueológico Provincial de Sevilla.

Pero, como bien decía Leonardo: "la desdicha suprema sobreviene cuando la teoría aventaja a la ejecución", el mayor potencial documental en manos de quince adolescentes y un profesor... en esta situación nace Itálica Virtual en 1996, a partir de una propuesta de Proyecto P.E.E. Comenius Action I de la U.E. denominado "Restauración Virtual"4, junto a otros tres institutos europeos: el ITIS Odone Belluzzi de Bolonia y los de Munich el Gymnasium Ottobrunn y el Wirtschaftsschule Pasold-Weissauer. Cuatro años de duro trabajo y setenta alumnos ilusionados que culminaron el I de abril de 2000 en Sevilla y el 26 de mayo en Bolonia, con la presentación pública de la casa del Planetario.

A partir de 2000 se ha ido terminando la ciudad y perfeccionando los modelos digitales en una incansable lucha entre el proyecto $y$ los nuevos recursos del software de los últimos tiempos. trabajado en la reconstrucción total (exterior e interior) de ocho edificios representativos de otras tantas tipologías funcionales de edificación; que son, como edificio lúdico y de espectáculos, el anfiteatro; como público, las termas de Adriano; como semipúblico, el Collegium de la Exedra; como defensivo, las puertas de la ciudad y la muralla; y por último, como edificios domésticos, las casas de los Pájaros y del Planetario de peristylum romano, y la casa de Hylas de perystilum rodio. Con respecto al parámetro temporal, se ha elegido el momento de máximo esplendor de Itálica, tras la gran ampliación de Adriano en el siglo II d. C.

Para conseguir una correcta reconstrucción arqueológica, tenemos que basarnos en una

\section{Mundo virtual}

Philippe Quéau lo define así: "un mundo virtual es una base de datos gráficos interactivos, explorable y visualizable en tiempo real y en forma de imágenes tridimensionales de síntesis, capaces de provocar una sensación de inmersión en la imagen. En sus formas más complejas, el entorno virtual es un verdadero espacio de síntesis, en el que uno tiene la sensación de moverse físicamente"s. Es por tanto, la realidad un conjunto de impresiones que colocan a los objetos aquí y ahora, en el espacio y en el tiempo y la realidad virtual un conjunto de 

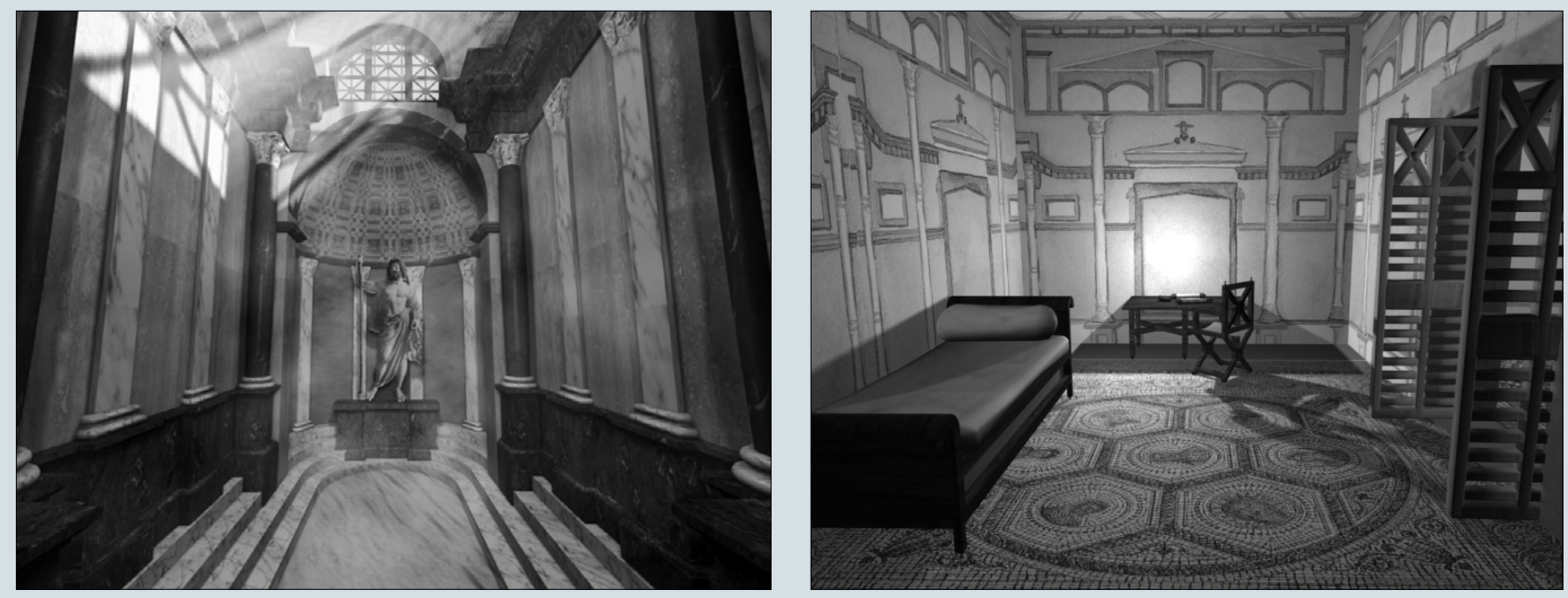

informaciones cuya función es sustituir la percepción espacio temporal del sujeto.

Estamos ante definiciones pioneras de una dimensión importante de las nuevas tecnologías informáticas: la virtualidad. Si las analizamos, encontraremos que el efecto de la realidad virtual o la animación en espacios 3D no es nada nuevo. ¿No es verdad que la literatura crea universos virtuales en nuestra mente?, y el teatro en general, ¿no se desarrolla en un espacio ficticio de síntesis?...

\section{Proceso creativo}

Para el desarrollo del proyecto hemos agrupado las distintas tareas a desarrollar por unidades didácticas; algunas nos han ocupado todo el proceso mientras que otras momentos puntuales. La secuencia metodológica es la siguiente: documentación, digitalización 2D, maquetas y estudio topográfico, levantamientos 3D, decoración, representaciones y animaciones $3 \mathrm{D}$ y producto final.

\section{Documentación}

El trabajo de documentación ha tenido su mayor relevancia en las primeras fases del proyecto, pero ha estado presente a lo largo de toda la experiencia. Los objetivos de este trabajo de documentación han sido formar a los alumnos sobre todos los aspectos concernientes al tema de investigación y servir de referencia documental para los diseños posteriores.
Al comienzo de la investigación recopilamos cualquier tipo de información que nos pudiera ser útil, realizamos una campaña de medición y acotación en Itálica con el objeto de conocer directamente el campo de trabajo y conseguir un banco de datos sobre la ciudad. En dichas visitas, medimos y acotamos tanto calles (cardos y decumanos), como todas las casas que íbamos a digitalizar posteriormente. Como complemento formativo, visitamos los Museos Arqueológicos de Madrid, Sevilla, Mérida y Córdoba y los conjuntos arqueológicos de Mérida y Carmona.

A lo largo del proyecto hemos visitado también numerosas bibliotecas para consultar fondos bibliográficos relacionados con el tema de trabajo. Así, la Biblioteca del Museo Arqueológico, Rectorado, Facultad de Bellas Artes Santa Isabel de Hungría, Laboratorio de Arte de la Facultad de Geografía e Historia, Conjunto Arqueológico de Itálica, la del propio Colegio, e incluso la Biblioteca del Museo Arqueológico Nacional en Madrid.

Por ultimo, la fuente documental más importante de todas, la de los expertos, que nos han facilitado con su experiencia profesional un legado valioso de datos e informaciones especializadas, a través de diversas entrevistas, reuniones y conferencias.

\section{Digitalización 2D}

Previamente a este trabajo los alumnos recibieron un curso de formación, manejo y adaptación del programa AutoCAD 6 R- $14 \AA$, en $2 \mathrm{D}$, organizado e impartido por ellos mismos. La primera tarea que llevamos a cabo fue la digitalización de todos los mosaicos de Itálica, tomando medidas para hacerlo a escala, completando y reconstruyendo las zonas desaparecidas. Para ello partimos de análisis pormenorizados de cada una de las estancias de las casas, con acotaciones y documentación fotográfica. En un segundo nivel, accedimos a la digitalización de todas las plantas de los edificios virtuales.

Posteriormente tratamos de obtener una digitalización total de la planimetría del municipio de Santiponce, lugar donde se ubica la ciudad romana. Para ello, dividimos el trabajo en varios grupos, de tal manera que uno se encargaba de las curvas de nivel, otro de los cultivos y carreteras, un tercero de las viviendas actuales y por último de lo que son las ruinas de Itálica, distinguiendo siempre lo que está en la superficie y lo que aún permanece enterrado.

\section{Maquetas y estudio topográfico}

El objetivo fundamental de esta fase ha sido el conocimiento exhaustivo de la topografía de Itálica. Para ello nos dedicamos al estudio previo de planimetrías, tanto parciales como totales de la ciudad y desarrollamos varias maquetas tridimensionales del conjunto arqueológico, que nos sirvieron de referencia a la hora de realizar las plantas y alzados de los edificios y el diseño del viario. 
En primer lugar se realizó una maqueta del relieve actual, a partir de la cual los topógrafos concretaron cual sería el aspecto del relieve en el siglo II d. C., teniendo en cuenta las zonas de mayor cota y mayor erosión y las de menor altura, a las que les corresponde un depósito masivo de materiales. De este modo, pudimos rectificar todas aquellas variaciones que tanto el tiempo como las personas han ido realizando en la zona. Para la realización de esta maqueta contamos con planos de la zona que contenían curvas de nivel a escala y de una categorización por colores.

Una segunda maqueta se realizó en dimensiones mayores $\left(6 \mathrm{~m}^{2}\right)$ en poliéster a escala ।:500 y ocho maquetas a escala 1:100 de los edificios virtuales, aquellos que iban a ser reconstruidos en su totalidad. Las maquetas están realizadas en cartón pluma y presentan un gran nivel de detalles.

\section{Levantamientos 3D}

En primer lugar, teniendo en cuenta las herramientas que poseíamos, llevamos a cabo la estructuración del proyecto 3D, es decir, decidimos cómo iba a ser el resultado que finalmente sería expuesto. Esto nos permitía proponer los objetivos concretos y delimitarlos en función del tiempo y de los alumnos. De este modo, llegamos a la conclusión de que ofreceríamos tres estadios:

- Una vista aérea de la ciudad, por la cual podríamos captar diversos puntos de vista generales.

- Una visita de alta definición por el interior de algunas casas y edificios de la ciudad.

- Imágenes fijas de alta definición de algunas zonas de la ciudad.

Por otro lado, a pesar de haber realizado ya unas primeras pruebas de lo que queríamos, nuestro equipo contaba con una gran limitación: el desconocimiento por parte de casi todo el alumnado del programa AutoCAD R-I4@, en 3D. Para superar esta dificultad, al igual que se hizo con la representación 2D, comenzamos nuestra incursión en las tres dimensiones con un primer curso de formación. En éste se aprendió el entorno gráfico del programa, las formas sólidas primitivas, los comandos básicos de edición, operaciones booleanas y las extrusiones de objetos.

El proceso de reconstrucción en 3D se llevó a cabo a partir de las plantas bidimensionales y partiendo de un dibujo prototipo con vistas ortogonales de alzado, planta, perfil y una axonometría. Cuando se cotejaron los datos y las mediciones, elevamos las cotas definitivas en una estructura alámbrica tridimensional. Los volúmenes sólidos se plantearon a partir de primitivas y operaciones booleanas entre ellas.

Nuestro primer trabajo fue la digitalización de la topografía de la ciudad. Hay que destacar que la topografía de la que hablamos era estudiada, al mismo tiempo que introducida en el ordenador, mediante maquetas que los alumnos confeccionaban para obtener una idea de la topografía en el siglo II d. C.

A partir de ahí el trabajo se centró en el desarrollo de una casa italicense completa, tanto el exterior como el interior. Ello supuso la creación de todos los elementos ornamentales que componían la decoración y el mobiliario de la vivienda, utilizando para ello las posibilidades que ofrece los programas de infografía.

\section{Decoración}

El resultado virtual va a depender, en gran medida, del nivel de representación de la realidad. El exterior y el interior de los edificios romanos contenían discursos decorativos propios: pintura mural, escultura, mosaicos y artesonados. El objetivo de esta unidad era llevar a cabo la reconstrucción completa de gran parte de los mosaicos existentes en Itálica, reintegrar y estudiar su color y textura, crear pinturas murales neutras que faciliten la comprensión del conjunto y de las esculturas existentes. Todo ello se reintegraba después dentro de las tres dimensiones de las viviendas, creando así el efecto virtual. Cada estancia era creada y decorada partiendo a partir de su función, la paleta de color de su mosaico y sus dimensiones.

Mosaicos: La metodología seguida en la reconstrucción de los mosaicos partía de la documentación fotográfica, así como sus res- pectivas medidas detalladas y un esbozo básico del color de las tesellae. Tras haber estudiado los documentos se procedió a diseñar cada uno de los mosaicos con AutoCAD R$14 \AA, 2 D$, teniendo en cuenta las medidas $y$ restituyendo con el mayor rigor posible las partes inexistentes del mosaico. Debemos tener en cuenta que gran parte de éstos han sido dañados por el paso del tiempo, lo que dificultó la labor de reconstrucción. A continuación se procedió a imprimir pequeños trozos de los dibujos en distintos papeles especialmente ideados para la acuarela o el gouache, medios que en principio serían utilizados para añadir el color y la textura sobre los dibujos. Se hicieron varias pruebas con el fin de dictaminar cuál era la opción más válida y tras haber completado el color los mosaicos se "teselaron" a plumilla y tinta china.

Pintura mural: Por su parte el estudio de las pinturas murales siguió un proceso similar a los mosaicos. Se elaboró un completo programa iconográfico de la pintura romana en toda su historia, se diseñaron en AutoCAD R-I4®, en 2D. A partir de unos estudios previos en papel, se tranquilizó la paleta de color y se adaptaron los diseños a las diferentes estancias, en un criterio de reconstrucción neutro, que no compitiese en ningún caso con el protagonista documental: el pavimento de mosaico, testigo mudo del esplendor del edificio.

Artesonados: A partir de la documentación fotográfica, desarrollamos distintos modelos de artesonados polícromos y yeserías, de igual manera que la pintura mural.

Escultura: Nos introducimos ahora en la tipología artística que más quebraderos de cabeza nos ha dado en su representación, en principio por su dificultad, y en segundo lugar por el elevado consumo de memoria que conlleva una estructura digital de millones de vértices. Para su digitalización hemos partido de la simplificación formal 2D, desarrollando un banco de esculturas de arte romano bidimensionales coloreadas a mano. Como experiencia singular se llevó a cabo un levantamiento en malla 3D de la Venus de Itálica.

Mobiliario y objetos 3D: Desarrollo tridimensional de todo el mobiliario de las edificaciones; triclinios, mesas, lechos, sillas, lámparas, lucernas y objetos 3D en general. 

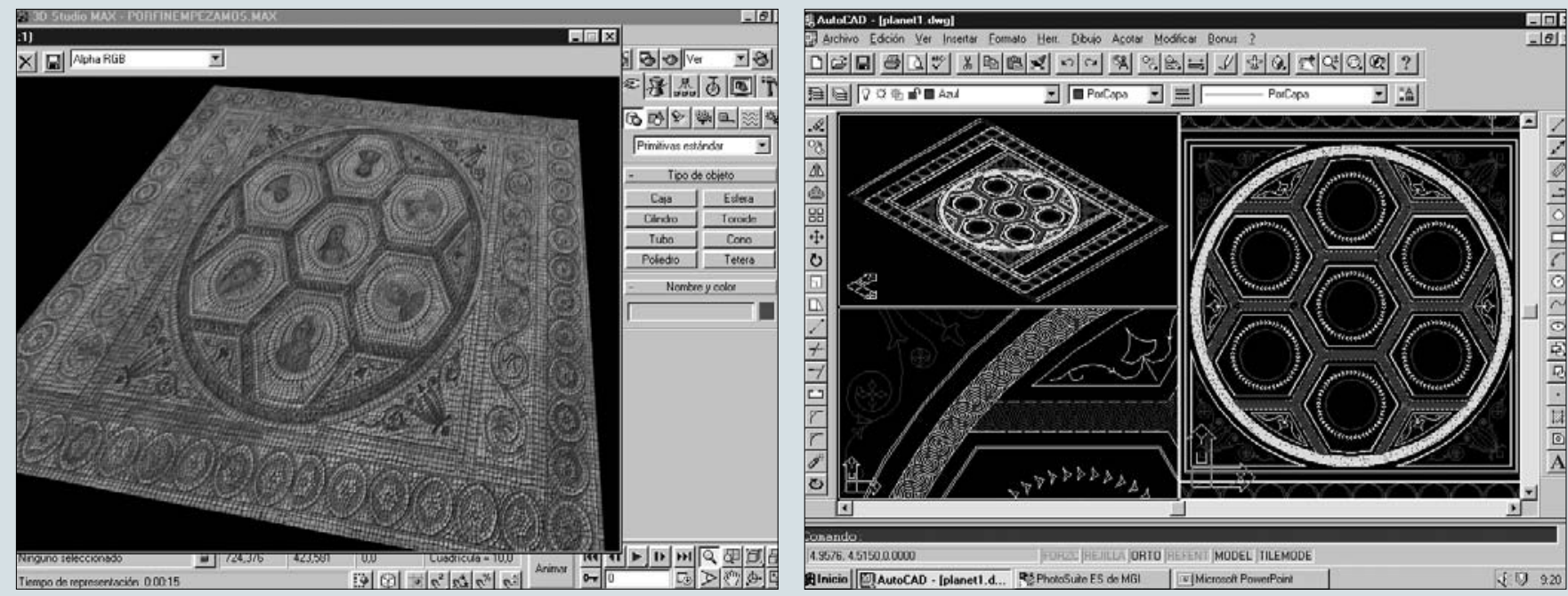

\section{Representaciones y animaciones 3D}

Los objetivos de esta fase eran varios. En primer lugar, formar en el uso del programa 3D Studio $M A X^{7}{ }^{\circledR}$, en edición de materiales, aplicación de mapas, colocación de luces y cámaras, así como el render de escenas. Igualmente se pretendía aprender los nuevos programas VRML orientados a Internet y crear una visita de alta definición en tiempo real por el interior de algunas casas y edificios de la ciudad en un entorno fotorrealista ${ }^{8}$.

Una vez terminados los levantamientos se insertaron todos los mapas específicos a los programas decorativos de las distintas estancias, mosaicos, pinturas murales, escultura y artesonados. Después se montaron en las maquetas digitales los mapas que reproducen los materiales y las calidades de la realidad, piedra, mármol, madera, bronce, etc., que van a constituir las texturas del mobiliario y de los objetos 3D.

Construidos los platós virtuales pasamos a la iluminación fotorrealista de las estancias interiores y exteriores, analizando la luz de Sevilla en las distintas horas del día, mañana, mediodía, tarde y noche. El siguiente paso consistió en la creación de trayectorias de cámara subjetiva que imitaran el transitar de una persona por los ambientes recreados sintéticamente. Al mismo tiempo que creamos secuencias virtuales, introdujimos animaciones del agua de las fuentes y del fuego de lámparas y lucernas. La fotografía secuencial en dicha trayectoria nos compone las imágenes fijas de alta definición que constituirán la futura ani- mación tras el arduo proceso de renderizado de todos y cada uno de los fotogramas.

Para terminar, tenemos la inserción de imagen humana dentro de los ambientes virtuales. Para ello hacemos uso de la técnica chroma' de postproducción, que nos permite insertar imagen real de actores en los espacios de síntesis, siguiendo un escrupuloso guión técnico y storyboard de producción. Una vez terminado el montaje definitivo sólo nos queda introducir los efectos de sonido, música y locución.

\section{Producto final}

La experiencia que presentamos culmina un vasto proyecto de investigación multidisciplinar desarrollado en dos fases sucesivas: de 1996 a 2000 y de este último año hasta nuestros días. La primera concluyó con la presentación pública internacional del $\mid$ de abril en el Palacio Yanduri de Sevilla y el 26 de Mayo en la Casa Cervantes del Colegio de España en Bolonia, Italia.

Pero como colofón al trabajo de investigación, los resultados de la segunda etapa se presentarán en el Museo Arqueológico Nacional de Madrid en el primer trimestre de 2003, con la exposición ITÁLICA VIRTUAL. Durante los dos meses de la muestra, se desarrollará en el Museo un ciclo de conferencias sobre el mundo romano y cultura clásica de manos de los más destacados investigadores del panorama actual. La muestra temporal de carácter itine- rante visitará una serie de museos y centros de arte, hasta llegar a Sevilla, en una fecha aún sin determinar.

Los productos desarrollados por el proyecto Itálica Virtual son:

\section{Dimensión documental:}

- Banco documental de digitalización CAD en 2D.

- Banco documental levantamientos CAD en 3D.

- Banco documental de mosaicos, pinturas murales, esculturas, artesonados, mobiliario y objetos 3D.

Dimensión maqueta física:

- Maqueta de Itálica a escala 1:500.

- Maqueta de la Casa del Planetario a escala I:100.

- Maqueta de la Casa de los Pájaros a escala I:100.

- Maqueta de la Casa de Hylas a escala I:I00.

- Maqueta de la Casa de la Exedra a escala I:100.

- Maqueta del Traianeum a escala 1:100.

- Maqueta de las termas Mayores a escala I:100.

- Maqueta del Anfiteatro a escala 1:100.

- Maqueta de la Puerta y Muralla a escala ।:100.

Dimensión maqueta electrónica:

- Maqueta de Itálica.

- Maqueta de la Casa del Planetario.

- Maqueta de la Casa de los Pájaros.

- Maqueta de la Casa de Hylas.

- Maqueta de la Casa de la Exedra.

- Maqueta del Traianeum. 
- Maqueta de las termas Mayores.

- Maqueta del Anfiteatro.

- Maqueta de la Puerta y Muralla.

\section{Dimensión audiovisual:}

- Cortometraje documental Itálica. Casa del Planetario de 13 minutos.

- Cortometraje documental Itálica Virtual de 26 minutos.

- Cortometraje documental Itálica Virtual de 12 minutos.

\section{Dimensión realidad virtual:}

- VRML Casa del Planetario.

\section{Dimensión web:}

- Página Web proyecto P.E.E.

http: //bellquel.scuole.bo.it/attivita/restore.

- Página Web Concurso Quincquest.

\section{Dimensión publicación:}

- Virtual Restoration, a Comenius project ITIS Odone Belluzzi. Bolonia. 2000

- Itálica Virtual. Colegio de San Francisco de Paula. Sevilla. 2003.

\section{Proceso pedagógico}

Desde el principio se consideró que el Proyecto, tanto por su extensión como por su alto grado de especialización, desbordaba el ámbito de las asignaturas curriculares, por lo que se convierte en una actividad de ampliación del curriculum, no evaluada académicamente, que será seguida y controlada por el coordinador del Proyecto.

\section{Aprendizaje significativo y cooperativo}

Hemos concebido el proyecto como un proceso constructivo en el que la actitud que mantienen profesor y alumno permite el aprendizaje significativo. El alumno se convierte en motor de su propio proceso de aprendizaje al modificar él mismo sus esquemas de conocimientos y las experiencias previas del profesor con los nuevos conceptos.

Todo esto se ha visto acentuado por la integración en el equipo de alumnos de diversos niveles educativos del Centro, e incluso con antiguos alumnos que, pese a haber terminado sus estudios a lo largo de la experiencia, han querido seguir participando en la misma. De este modo se ha roto con el esquema rígido de niveles educativos aislados entre sí, fuertemente jerarquizados, dando paso a la comunidad de aprendizaje significativo.

\section{Equipo multidisciplinar}

La reconstrucción arqueológica de un monumento perdido como el que nos ocupa necesita de una base histórica importante, por lo que desde un principio se formó un equipo técnico interdisciplinar formado por distintas disciplinas, historiadores, arqueólogos, arquitectos, artistas, ingenieros, informáticos, etc. Este estilo de trabajo multidisciplinar se ha reproducido dentro el equipo, habiéndose desarrollado especializaciones de los 70 alumnos participantes en tareas tales como el dibujo, el trabajo con $C A D$, diseño de páginas web, retoque fotográfico, trabajo 3D, elaboración de maquetas, etc.

Por otra parte, la gran variedad de funciones que exige un trabajo como este nos ha permitido desarrollar un principio pedagógico de gran importancia: la atención a la diversidad, ya que cada alumno participante ha podido encontrar la función más adecuada a sus posibilidades e intereses, facilitándose así una adaptación del proceso de enseñanza-aprendizaje a las características individuales de cada uno de los integrantes del equipo.

\section{Metodología activa y formación para la acción}

Uno de los aspectos pedagógicos que nos interesa resaltar de la experiencia ha sido su carácter de aprendizaje activo, centrado en la solución de problemas reales, orientado a la acción en la vida real, externa al Centro. El entorno ha estado siempre presente, desde las visitas iniciales al contacto con expertos, el uso de programas informáticos profesionales y la preparación de los distintos eventos relacionados con el Proyecto.

\section{El desarrollo de actitudes y valores}

Una experiencia de estas características permite desarrollar un amplio abanico de actitudes y valores en sus participantes, ampliando con ello su carácter educativo, más allá de los aspectos puramente instructivos. Los alumnos han podido vivir la experiencia de un trabajo voluntario, sin limitarse al cumplimiento de las estrictas exigencias académicas ligadas a la evaluación de las materias. Esto les ha ayudado ha desarrollar la capacidad de trabajar por el interés de la tarea en sí misma, y no buscando la recompensa de las calificaciones.

Una de las actitudes que más se han potenciados a lo largo de la experiencia ha sido, sin duda, la voluntad y el esfuerzo continuado aplicados a una tarea en la que los resultados se consiguen a muy largo plazo. Ello ha sido así hasta tal punto que muchos de los integrantes del equipo han terminado sus estudios en el Centro sin poder culminar el Proyecto, aunque han realizado su aportación a la tarea global.

Por último, como consecuencia de todo lo anterior, y quizás para nosotros lo más importante del trabajo, es necesario hablar de los lazos afectivos que se han creado entre los participantes en el Proyecto. El trabajo ha servido para crear un espíritu de grupo y de amistad que perdurará, si no tanto como las ruinas que se están restaurando, sin duda mucho más allá de la finalización de la experiencia.

\section{Hardware, software e instalaciones}

Inicialmente el Proyecto contó con los recursos informáticos del Centro, pero a medida que avanzó en su desarrollo, la especialización y complejidad de las tareas, y la cada vez mayor intensidad del trabajo, fueron requiriendo de recursos dedicados exclusivamente a la experiencia.

En lo que se refiere al hardware, comenzamos con 5 ordenadores Pentium ® $200 \mathrm{Mhz}$ con 32 y $64 \mathrm{Mb}$. de RAM, conectados en red, unidos a Internet a través de la red local del Centro. Cada equipo contaba con un disco duro de $2 \mathrm{~Gb}$. Estos recursos se mostraron muy pronto claramente insuficientes y se fueron incrementando continuamente hasta 4 Pentium III 550 Mhz. y I Pentium II 233 $\mathrm{MHz}$, con 512 y $256 \mathrm{Mb}$ de RAM, discos de 6,4 a 20 Gb. y tarjetas gráficas de $8 \mathrm{Mb}$, una digitalizadora de vídeo Matrox RT $2000 \AA$, scanner Agfa SnapScan $\circledR_{\text {y }}$ y una grabadora de CDs Philips ${ }^{\circledR} 2 x$. 

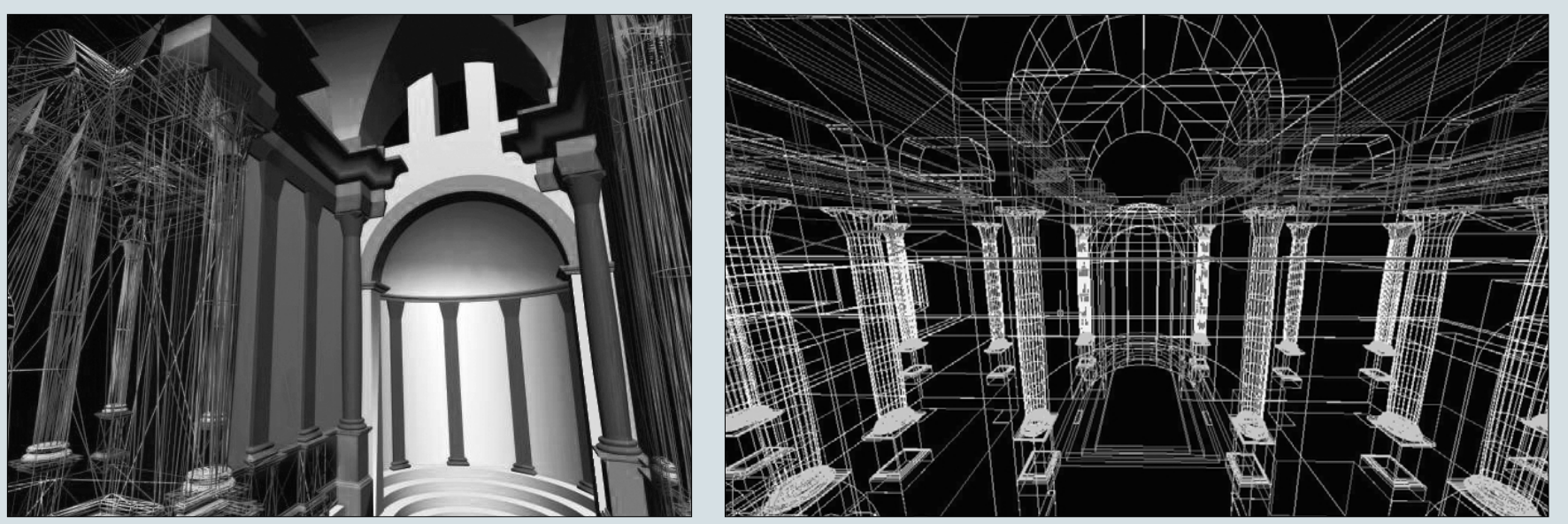

En lo que se refiere al software, los programas básicos que se utilizaron son los siguientes:

- AutoCAD R 13/I4@ y $2000 @$

- 3D Studio Max v. $3.0 \AA$

- Adobe Photoshop $5.5 \AA$

- Adobe Premier $5.1 \circledR$

- FrontPage $97 \AA, 98 ®$ y $2000 \AA$

Por último, contamos con las instalaciones:

- Aula de Restauración virtual de $35 \mathrm{~m}^{2}$.

- Plató virtual chroma de $10 \mathrm{~m}^{2}$.

- Aula taller de Tecnología de $150 \mathrm{~m}^{2}$.

- Aula CAD de Tecnología de $15 \mathrm{~m}^{2}$.

\section{Conclusiones}

La experiencia presentada ha resultado una vivencia educativa única y de gran intensidad para todos los participantes. Ha permitido trabajar sobre objetos de estudio de la propia realidad, con un alto grado de profesionalización y especialización, generando nuevos procesos de aprendizaje más dinámico y abriendo perspectivas vocacionales a algunos de los miembros del equipo. Nuestra valoración global es, por tanto, muy positiva, y pensamos que el esfuerzo realizado ha valido la pena para todos, no sólo por los productos que se han obtenido, de una indudable calidad, sino muy especialmente por el propio proceso, considerado por todos como una rica experiencia innovadora dentro del contexto escolar.

Si bien somos conscientes de que es difícil (pero no imposible) repetir proyectos de este tipo en cualquier centro, por su carácter singular y los cuantiosos medios que requie- re, ello no es obstáculo, a nuestro juicio, para extraer de la experiencia las líneas pedagógicas maestras que la guían para transponerlas a otros trabajos. Creemos que es una buena muestra de un uso intensivo y a la vez creativo de las nuevas tecnologías en el campo del patrimonio, apoyándose en su carácter integrador y multidisciplinar, que ha permitido abordar problemas de muy diversas disciplinas desde una perspectiva integradora que les dota de sentido propio, y enseña a los alumnos a acercarse a la vida desde el aprendizaje escolar

\section{Notas}

I. La perspectiva óptica es la modalidad de proyección con la que estamos más familiarizados. Fue formulada de manera sistemática en los albores del Renacimiento en Florencia. Utiliza como base el hecho de que las líneas paralelas parecen converger y los objetos parecen hacerse más pequeños cuanto más lejanos están del espectador.

2. El carácter pionero de ITÁLICA VIRTUAL (I996 comienzo del proyecto) se constata con la timidez con la que la creación de modelos digitales históricos se ha introducido en España. Hasta el 2000 con el proyecto Complutum $3 / 3$ d. C. o el Mendavia, sólo se conocen modelos muy puntuales de edificios o pequeños yacimientos. Actualmente están en marcha modelos digitales de Tarragona y Lucentum, por citar algunos.

3. Anastilosis es en arqueología la reconstrucción de un edificio en ruinas, llevada a cabo en su mayor parte, con los elementos hallados en el lugar y de acuerdo con los principios arquitectónicos en vigor en la época de su erección. Etimológicamente del griego, anastylos; "sobre columnas'.

4. El proyecto Restauración Virtual (Comenius Action I) trata de reconstruir y restaurar por medio del diseño asistido por ordenador y realidad virtual, conjuntos muy deteriorados o ilegibles en sus estructuras originales. Virtual Restoration es un Proyecto Educativo Europeo P.E.E. de la Agencia Nacional Sócrates. AA.VV. Virtual Restoration, a Comenius project. ITIS Odone Belluzzi. Bolonia. 2000. http://bellquel.scuole.bo.it/attivita/restore
5. QUÉAU, Ph. Lo Virtual. Virtudes y Vértigos. Paidós. Madrid. 1995. pp. 15-16.

6. AutoCAD R-I4 $₫$ es una potente herramienta informática de CAD (Computer Aided Design), programa líder del diseño tridimensional asistido por ordenador, que sustituye el trazado tradicional por la infografía 2D. S/A; Manual de AutoCAD release 13. Autodesk. Madrid. 1994

7. $3 D$ Studio $M A X \circledast$ es un programa de infografía para PC. Incluye todas las características de este tipo de software; sistemas de modelado $2 \mathrm{D}$ y $3 \mathrm{D}$, editor de materiales, render y animación. S/A; Manual de 3D Studio MAX Kinetics. Madrid. 1998.

8. El fotorrealismo denomina en un ambiente virtual, el crear imágenes que se aproximen lo más posible a la realidad, a lo que una cámara fotográfica captaría tras una exposición. El fotorrealismo lucha con la impresión fría de las "maquetas electrónicas", que confieren aspecto sintético y sin vida a las representaciones tridimensionales de la realidad.

9. Chroma es la técnica de postproducción donde un fondo neutro de color homogéneo es anulado del positivo de la película e insertado un fondo virtual que sustituye al primero en el montaje definitivo. Es una técnica apropiada para la mezcla de imagen real y virtual en una producción audiovisual. Para su creación se necesita un plató virtual "sin fin", normalmente de color azul o verde, donde se realizan las grabaciones de imagen real.

\section{Bibliografía}

AA.V. Restauración Virtual de Itálica. Concurso Proyectos Educativos Santillana. Madrid. 1998.

AA.W. Restauración Virtual de Itálica. Cuadernos de Educación Europeos. Generalitat de Cataluña. Tarragona. 1998.

AA.V. Virtual Restoration, a Comenius project. ITIS Odone Belluzzi. Bolonia. 2000.

DE LA TORRE, S. "Creatividad Plural". Ediciones DPU. Barcelona. 1993.

GÓMEZ CONSEGURA, L. "La Catalogación abierta: Una posibilidad Actual para la Conservación del Patrimonio". Ponencia VI Conferencia Internacional sobre Conservación de Centros Históricos Iberoamericanos. Universidad de Comahue. Cuba. 1994.

QUÉAU, Ph. Lo Virtual. Virtudes y Vértigos. Paidós. Madrid. 1995. 